
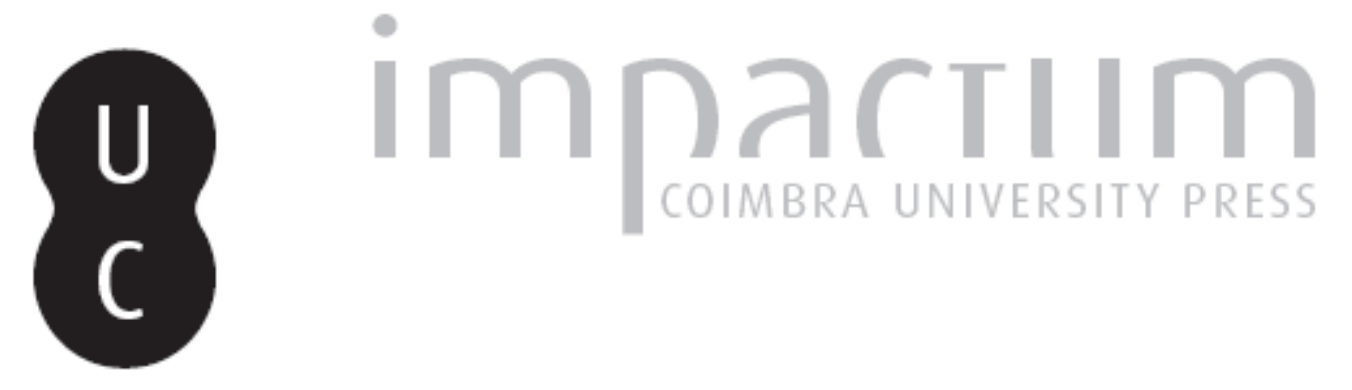

\title{
Física e Filosofia antiga em Werner Heisenberg: apropriações do legado clássico por um físico do século XX
}

Autor(es): $\quad$ Leite, Anderson Cleiton Fernandes; Simon, Samuel

Publicado por: Annablume Clássica

URL persistente:

URI:http://hdl.handle.net/10316.2/24513

DOI:

DOI:http://dx.doi.org/10.14195/1984-249X_11_2

Accessed : $\quad$ 26-Apr-2023 13:19:39

A navegação consulta e descarregamento dos títulos inseridos nas Bibliotecas Digitais UC Digitalis, UC Pombalina e UC Impactum, pressupõem a aceitação plena e sem reservas dos Termos e Condições de Uso destas Bibliotecas Digitais, disponíveis em https://digitalis.uc.pt/pt-pt/termos.

Conforme exposto nos referidos Termos e Condições de Uso, o descarregamento de títulos de acesso restrito requer uma licença válida de autorização devendo o utilizador aceder ao(s) documento(s) a partir de um endereço de IP da instituição detentora da supramencionada licença.

Ao utilizador é apenas permitido o descarregamento para uso pessoal, pelo que o emprego do(s) título(s) descarregado(s) para outro fim, designadamente comercial, carece de autorização do respetivo autor ou editor da obra.

Na medida em que todas as obras da UC Digitalis se encontram protegidas pelo Código do Direito de Autor e Direitos Conexos e demais legislação aplicável, toda a cópia, parcial ou total, deste documento, nos casos em que é legalmente admitida, deverá conter ou fazer-se acompanhar por este aviso.

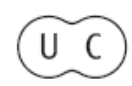



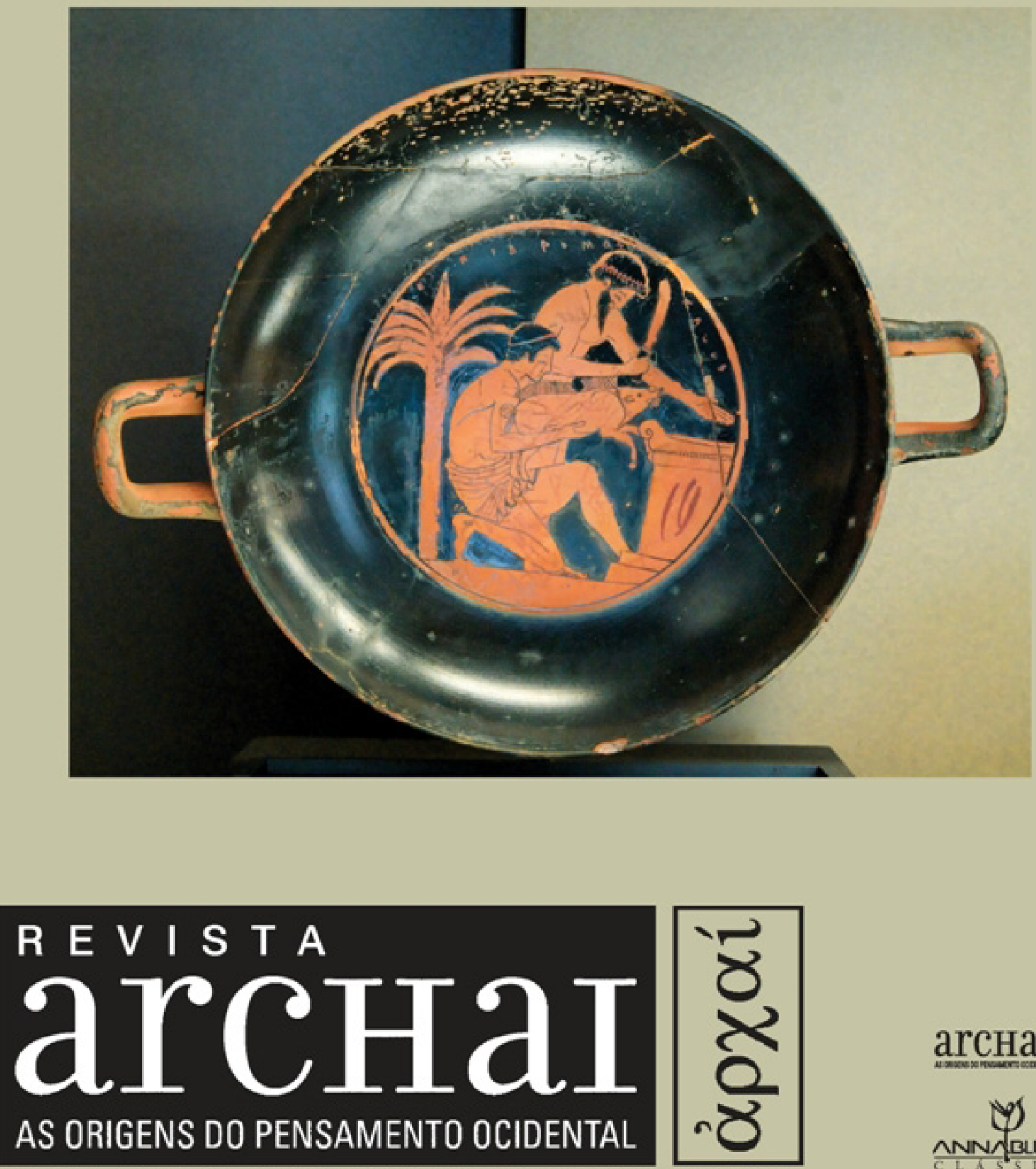

ARCHAI JOURNAL: ON THE ORIGINS OF WESTERN THOUGHT

arcHaI凰

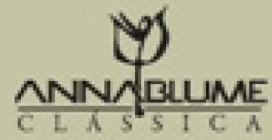




\section{FÍSICA E FILOSOFIA ANTIGA EM WERNER HEISENBERG: APROPRIAÇÕES DO LEGADO CLÁSSICO POR UM FÍSICO DO SÉCULO XX}

LEITE, A. C. F.; SIMON, S. (2013). Física e Filosofia Antiga em Werner Heisenberg: apropriações do legado clássico por um físico do século XX. Archai, n. 11, jul-dez, p. 21-32.

RESUMO: 0 objetivo deste artigo é analisar os usos que Werner Heisenberg fez da filosofia grega em sua obra. Pretende-se relacionar tais usos não apenas com a argumentação interna presente nos textos do fisico alemão, mas também com o contexto histórico, conflitos e debates entre as diversas interpretações da teoria dos quanta durante a primeira metade do século XX. Faremos, inicialmente, uma apresentação geral da teoria quântica e da presença da filosofia na obra de Heisenberg e, em seguida, um estudo de caso da apropriação que Heisenberg fez do pensamento de Leucipo, Demócrito, Heráclito, Platão e Aristóteles.

PALAVRAS-CHAVE: Werner Heisenberg; Filosofia Antiga; Física Quântica; Filosofia da Física e Legado Clássico.

ABSTRACT: The aim of this article is to analyze the uses Werner Heisenberg made of Greek philosophy in his works, and to relate such uses not only to the internal argumentation present in the texts of the German physicist, but also to the historical context, conflicts and debates between diverse interpretations of quantum theory during the first half of the 20th century. We shall first make a general presentation of the quantum theory and the presence of philosophy in the works of Heisenberg, followed by a case study of Heisenberg's appropriation of the thought of Leucippus, Democritus, Heraclitus, Plato and Aristotle.

KEYWORDS: Werner Heisenberg; Ancient Philosophy; Quantum Physics; Philosophy of Physics.

\section{Anderson Cleiton Fernandes Leite* Samuel Simon**}

\author{
Em vez de ver os gregos como inventores, seria \\ melhor considerá-los como invenção. \\ Cada época constrói os seus. \\ Roger-Pol Droit
}

Tal como Copérnico e Galileu abandonaram, nos seus métodos, a ciência descritiva de Aristóteles, assim seremos forçados a abdicar do materialismo atômico de Demócrito e a retomar as idéias de simetria da filosofia de Platão. Werner Heisenberg

\section{Considerações iniciais}

Afirmar a proeminência da tradição clássica na constituição do mundo ocidental tornou-se, sem dúvida, um lugar-comum. Entretanto, tal evidência não retira a veracidade do fato de que a herança clássica conformou - e ainda conforma - grande parte das instituições, práticas e crenças do Ocidente. Não significa que a recepção dessa tradição tenha sido a prática de uma mera repetição dos modelos greco-latinos. A despeito de a palavra tradição remeter a uma acolhida complacente e passiva diante do legado clássico, ele foi objeto de um sem-número de apropriações e reinterpretações. 0 que, em certa medida, permitiu 
o surgimento de uma nova Grécia a cada tradição intelectual que dela se referia.

Dado esse contexto, o presente artigo analisa um pequeno capítulo na longa história da recepção do legado helênico pela cultura européia. A obra de um dos mais importantes físicos do século XX, Werner Karl Heisenberg (1901-1976), é perpassada por conceitos advindos das filosofias de Platão, Aristóteles e mesmo dos pré-socráticos. Nas palavras do próprio Heisenberg (1952, p. 96):

Para se adquirir uma compreensão dos fundamentos da física atômica, nós devemos seguir, passo a passo, as idéias que, dois mil e quinhentos anos atrás, conduziram a filosofia natural grega à teoria atômica; devemos então tentar encontrar uma conexão com essas idéias fundamentais mesmo nos avanços mais modernos da física atômica.

Já em um artigo de $1932^{1}$, o primeiro do físico alemão a se referir diretamente à filosofia grega, até um discurso de 1964 proferido em grego na colina Pnix em Atenas (HEISENBERG, 1974, p. 107-111), Heisenberg aborda problemas da física quântica utilizando-se de conceitos da filosofia grega. Não surpreende, então, a sua defesa de que:

Quem queira chegar até ao fundo das coisas em qualquer especialidade [...] se chocará com aquelas fontes antigas e daí tirará grandes benefícios para 0 seu próprio trabalho, por ter aprendido com os gregos a pensar de uma maneira geral, a transportar os problemas para o plano teórico (HEISENBERG, 1962, p. 63).

Desta forma, o objetivo deste trabalho é analisar os usos que Heisenberg fez da filosofia grega, e relacioná-los não só com a argumentação presente nos textos do físico alemão, mas também com o contexto histórico de conflitos e debates entre as diversas interpretações da teoria dos quanta. Faremos, inicialmente, uma apresentação geral da teoria quântica e da presença da filosofia na obra de Heisenberg e, em seguida, um estudo da apropriação que Heisenberg fez do pensamento de Leucipo, Demócrito, Heráclito, Platão e Aristóteles ${ }^{2}$.

\section{A teoria dos quanta}

\section{A Mecânica Quântica trata do comportamento} físico da matéria em nível atômico e subatômico, o que faz dela uma das teorias fundamentais da física. Seu poder preditivo é notável e a aplicabilidade da teoria é extremamente vasta, bastando citar, por exemplo, o papel preponderante da mecânica quântica na invenção do diodo e do transistor e o impacto destes sobre a eletrônica e a informática. Apesar de sua aceitação entre a comunidade científica ser inegável, a mecânica quântica, desde sua criação, é marcada por uma série de controvérsias envolvendo sua interpretação. A imagem da natureza que pode ser construída a partir da teoria dos quanta é incompatível com aquela derivada da Física Clássica e das intuições ordinárias acerca do funcionamento do mundo físico.

A ruptura instaurada pela mecânica quântica atinge os fundamentos da própria física clássica em seus elementos mais básicos. Tal situação se reflete até mesmo no aparato matemático da teoria, bem diverso daquele utilizado pela mecânica clássica (BOHM, 1951, p. 1). Segundo o físico brasileiro Antônio Piza, “não é possível [...] deduzir a mecânica quântica de noções ou esquemas anteriores, nem tampouco construí-la como alguma forma de extensão de teorias clássicas" (2003, p. 2) ${ }^{3}$.

\section{0 cisma na física}

Desde os artigos de Einstein e de Max Planck (1858-1947), no início do século XX, iniciou-se um grande incômodo entre a comunidade dos físicos quanto aos aspectos ondulatórios e corpusculares demonstrados pela luz ${ }^{4}$. A expectativa era que uma das duas descrições antitéticas, partícula ou onda, seria, inevitavelmente, reduzida à outra, resolvendo o dilema.

Diante disso, o grupo ligado a Niels Bohr (1885-1962) acabou por aderir à concepção de que a nova física levava necessariamente ao abandono das concepções herdadas da mecânica clássica. Mais que isso: haveria uma profunda inadequação entre a linguagem ordinária, utilizada para descrever o mundo macrofísico, e os fenômenos quânticos. Entretanto, apesar de tal concepção ter se tornado
1. 0 título do artigo é "Zur Geschichte der physikalischen Naturklärung", tradução para o inglês em HEISENBERG, 1952, p. 27-40.

2. A relação entre a filosofia de Platão e os escritos de Heisenberg é analisada mais especificamente no artigo "Werner Heisenberg e a Interpretação de Copenhague: a filosofia platônica e a consolidação da teoria quântica" (LEITE; SIMON, 2010).

3. Vale notar que existem visões alternativas, no que concernem às interpretações da Mecânica Quântica. A esse respeito, ver Freire Jr., 2011, p. 33-64.

4. “Um sistema quântico ou exibe aspectos corpusculares (seguindo trajetórias bem definidas), ou aspectos ondulatórios (como a formação de um padrão de interferência), dependendo do arranjo experimental, mas nunca ambos ao mesmo tempo" (PESSOA Jr., 2005, p. 18). 
quase hegemônica desde o nascimento da teoria quântica, inúmeros físicos não aderiram a ela. Albert Einstein (1879- 1955) e Erwin Schrödinger (1887-1961), dentre outros, demonstraram sérias restrições ao modo como o grupo capitaneado por Niels Bohr compreendia a teoria. Essa situação provocou o que Karl Popper denominou de "cisma na física" no qual dois grupos se confrontaram (POPPER, 1989).

A interpretação de Copenhague, que se configurou como a visão hegemônica sobre o formalismo e os resultados experimentais da mecânica quântica, foi produto do trabalho de dois importantes centros de pesquisa: Göttingen, na Alemanha, representado por Max Born (1882-1970) e Pascual Jordan (19021980), e Copenhague, na Dinamarca, sob a liderança de Niels Bohr. Heisenberg serviu de elo entre os dois pólos, especialmente na década de 1920.

Bohr propõe que as diferentes descrições dos fenômenos quânticos, corpuscular ou ondulatória, não devem ser simplificadas ou dissolvidas uma na outra, mas sim vistas como complementares, tendo em vista uma unidade essencial, ou seja, somente "a totalidade dos fenômenos esgota as informações possíveis sobre os objetos" (BOHR, 1995, p. 51).

Em 1935, Bohr aprofundou suas idéias acerca do que seria um fenômeno no nível quântico. A noção de totalidade considera como fenômeno não só o objeto quântico, mas também toda a aparelhagem de na tese de que 0 indeterminismo encontrado na teoria quântica indicaria a incompletude dela, e até mesmo, o seu caráte provisório. Mas o que seria esse indeterminismo? Segundo Chibeni (1992, p. 147): “a mecânica quântica é uma teoria indeterminista, já que os resultados das observações futuras sobre o sistema nunca são todos determinados, mesmo quando presentemente conhecemos perfeitamente 0 estado quântico do sistema".

6. 0 quantum de ação é um term utilizado no início dos debates da teoria quântica para se referir à constante de Planck - $\mathrm{h}$ - que, de certa maneira, definiu o limite entre o domínio e o domínio clássico. Essa constante foi fundamental para a posterior quantização dos processos do domínio microscópico, como o quantum de energia da onda eletromagnética. que certos parâmetros, herdados das teorias clássicas - como o determinismo ${ }^{5}$, por exemplo - possam ser abolidos da representação dos fenômenos atômicos. Para muitos, e especialmente para Einstein, a renúncia total a um quadro conceitual clássico para os eventos reais fazia da teoria algo inaceitável. Um aprofundamento das críticas foi exposto, em 1935, no artigo "A descrição da realidade física fornecida pela mecânica quântica pode ser considerada completa?", assinado por Einstein juntamente com dois colegas, Boris Podolsky (1896-1966) e Nathan Rosen (1909-1995) (esse artigo ficou conhecido pela sigla "EPR"). É emblemática a frase de abertura do artigo, de forte cunho realista:

Qualquer consideração séria a respeito de uma teoria física deve levar em conta a diferença entre a realidade objetiva, que independe de qualquer teoria, e os conceitos físicos com os quais a teoria opera. Pretende-se que tais conceitos tenham correspondência com a realidade objetiva, e por meio deles construímos uma imagem dessa realidade (EINSTEIN; PODOLSKY; ROSEN, 1981, p. 90).

Para Bohr, as críticas apontadas por Einstein - por exemplo, o caráter incompleto da mecânica quântica - seriam superáveis em função de uma mudança de perspectiva quanto à natureza da própria física:

Na verdade a aparente contradição só põe a nu uma inadequação essencial da perspectiva costumeira da filosofia natural em fornecer uma descrição racional dos fenômenos físicos do tipo que estamos interessados na mecânica quântica. Com efeito, a interação finita entre objeto e agentes de medida, condicionada pela própria existência do quantum de ação ${ }^{6}$, implica - devido à impossibilidade de controlar a reação provocada pelo objeto nos instrumentos de medida, se estes devem servir a seus objetivos - a necessidade de uma renúncia final às idéias clássicas de causalidade, e uma revisão radical de nossa atitude perante o problema da realidade física [Grifo nosso] (BOHR, 1981, p. 98 - 99).

0 cisma na física, então, estabelece-se em um nível filosófico, e não apenas científico. As 
diferenças apontadas podem ser descritas como uma divergência quanto a ontologia que procede da teoria, ou seja, uma divergência acerca da descrição que a teoria fornece sobre o que há no mundo.

\section{A filosofia em Heisenberg}

Em fins do século XIX havia uma postura otimista quanto aos destinos da física para o próximo século. As seguintes palavras de Albert Michelson (1852-1931) ilustram tal ponto: "é provável que a maior parte dos grandes princípios básicos [da física] tenha sido firmemente estabelecidos e os próximos avanços sejam encontrados, sobretudo na rigorosa aplicação destes princípios a todos os fenômenos dos quais tenhamos notícia" (KRAGH, 2002, p. 3).

Pouco mais de 30 anos depois, Heisenberg parecia não partilhar desse otimismo. Ele se refere ao ano de 1925 nos seguintes termos: "A teoria quântica [...] era, naqueles dias, não uma teoria, mas um estorvo. Ao bem fundado edifício da física clássica, ela trouxe idéias que levaram, em muitos pontos, a dificuldades e contradições" (HEISENBERG, 1989, p. 37 - 38).

Bastaram trinta anos, cerca de uma geração, para que a situação da física mudasse drasticamente. A afirmação de Michelson, feita em 1894, apesar de cautelosa, assume tacitamente que as questões fundamentais da física já estariam resolvidas e, assim, o trabalho dos físicos seria aplicar uma série de princípios bem estabelecidos aos problemas vindouros. Em contrapartida, o comentário de Heisenberg caminha em uma direção oposta: certos princípios fundamentais da física, como a causalidade, não conseguem mais explicar características básicas da matéria.

Neste contexto de crise, Heisenberg apresentava, além das habilidades matemáticas e criativas necessárias para o trabalho com física teórica, interesse e intimidade com temas filosóficos, especialmente com a filosofia grega. A humanistische Bildung ${ }^{7}$ de Heisenberg, que poderia ser considerada inútil em sua carreira científica, tornou-se um instrumento intelectual que o permitiu enfrentar a crise na qual se encontrava a física de sua época.
0 trecho a seguir demonstra per si, e com uma incrível força retórica, o modo como Heisenberg via a história da ciência e da filosofia serem perpassadas pela presença da filosofia helênica:

A ciência moderna tem seguido algumas tendências da filosofia natural grega, pois tem reconsiderado uma série de problemas com que a filosofia havia se debatido em seus inícios [...]. Existem, especificamente, duas idéias da antiga filosofia grega que na atualidade ainda determinam o curso da ciência e que são, por essa razão, de especial interesse para nós: a convicção de que a matéria consiste de pequenas unidades indivisiveis, os átomos, e a crença na força de estruturas matemáticas (HEISENBERG, 1952, p. 53).

Segundo Heisenberg, na tentativa dos gregos de buscar "um entendimento unificado dos fenômenos naturais", surgiram "dois conceitos opostos": o idealismo e o materialismo. Ambos prescreviam diferentes respostas ao problema das menores partículas da matéria (HEISENBERG, 2004, p. 11).

A teoria atômica criada por Leucipo (fl.450420 a.C.) e Demócrito (c.460-c.370 a.C.) é considerada o marco fundador do materialismo. A outra corrente, o idealismo, seria representada pelo pitagorismo e por Platão, sendo encontrada mais especificamente no diálogo Timeu. Ambas as tendências, afirma Heisenberg, não são apenas duas vetustas doutrinas de interesse restrito a historiadores da filosofia. Para ele, a descoberta de Planck $^{8}$ não se limitou a resolver um problema relacionado à emissão de radiação térmica. Uma de suas consequiências foi reviver o debate entre Demócrito e Platão acerca dos constituintes últimos da matéria (HEISENBERG, 1974, p.10) ${ }^{9}$.

\section{0 materialismo de Demócrito e Leucipo e sua influência na história da ciência}

0 atomismo grego pode ser considerado uma tentativa de refutar os argumentos apresentados pela Escola Eleata, isto é, por Parmênides e seus seguidores, como Zenão e Melisso. Em resposta à antítese "Ser" e "Não-Ser", os atomistas propõem
7. Cf. LEITE; SIMON, 2010.

8. Ver acima nota 6 .

9. Heisenberg considera que a física moderna é mais próxima das concepções platônicas sobre a matéria apresentadas no Timeu do que do atomismo de Demócrito Cf. LEITE; SIMON, 2010. 
os conceitos de "átomo" e "vazio", como descreve Aristóteles (e.g. Aristóteles, De gen. et corr., 325a 23-32 apud KIRK, 1994, p. 430-431) .

Haveria uma tentativa, segundo Aristóteles, da teoria de Leucipo conciliar os dados dos sentidos em sua infinita variedade com a metafísica de Parmênides. Mas, ao contrário do monismo eleático, Leucipo defendia que o não-ser, no caso, o vazio, teria tanta existência quanto os átomos que nele se movem. E mesmo admitindo "a força dos argumentos de Zenão" sobre a divisibilidade infinita, Leucipo, segundo Burnet (2006, p. 352), teria dotado cada um dos átomos de "todos os predicados do Uno eleático".

Os átomos, deste modo, são caracterizados como invisíveis devido ao tamanho minúsculo, apesar de possuírem grandezas como tamanho e posição, além de serem fisicamente indivisíveis por não existir neles espaço vazio ${ }^{10}$. Como são formados pela mesma substância, não haveria entre eles uma diferenciação qualitativa. As únicas propriedades intrínsecas dos átomos são forma, tamanho e disposição no vazio. E o choque dos átomos gera o movimento. Essa movimentação no vazio é aleatória, sem finalidade e eterna e, juntamente com as formas e os arranjos dos átomos entre si, explica toda a variedade de objetos e seres observados no mundo. (TAYLOR, 1997, p. 204).

Um dos fragmentos mais conhecidos de Demócrito afirma que "Por convenção doce e por convenção amargo, por convenção quente, por convenção frio, por convenção cor; na realidade, porém, átomos e vazio" (DEMÓCRITO fr. 10 e 6-8, Sexto Adv. math. VII, 136 (DK B9)) $)^{11}$. As aparências são reduzidas a epifenômenos, derivados da atividade dos átomos no vazio, ou segundo a terminologia aristotélica: “os dois juntos [átomos e vazio] são as causas materiais das coisas existentes" (ARISTÓTELES, Met. A 4, 985 b 4 (DK 67 A 6)) $)^{12}$. Além de explicar a constituição dos corpos e das sensações, os átomos também estão na origem de atividades ditas espirituais: “a alma consiste em átomos esféricos espalhados pelo corpo, e, muito provavelmente, o espírito era considerado uma concentração destes átomos-alma" (KIRK, 1994, p. 453). 0s átomos constituintes da alma se diferenciariam dos demais apenas pela forma redonda, o que, comparado a outros átomos com formas mais estáveis, facilitaria sua movimentação. Mas as colisões e os agrupamentos entre eles no vazio ainda seriam a origem do movimento, assim como nos outros tipos de átomos (CORNFORD, 1957, p. 156). A doutrina atomista, dessa forma, além de materialista ${ }^{13}$, era marcada pela ausência de finalidade ou desígnio ${ }^{14}$ e, por isso, pode ser considerada o primeiro sistema mecanicista da história da filosofia.

A descrição que Heisenberg fez da teoria atômica antiga segue estritamente essa interpretação anterior:

A teoria atômica fundada por Leucipo e Demócrito considerava as menores partículas de matéria como "aquilo que existe" no sentido mais estrito. Tais partículas foram consideradas indivisíveis e imutáveis. Eram eternas e unidades últimas, não possuíam outras propriedades que não as geométricas. Segundo os filósofos, os átomos eram dotados de uma forma definitiva. Estavam separados entre si pelo espaço vazio e, graças às diferentes posições e movimentos neste espaço vazio, podiam produzir uma ampla variedade de fenômenos, mas não tinham cor, nem cheiro ou sabor, e muito menos temperatura ou outras propriedades físicas que nos são familiares. As propriedades das coisas por nós percebidas eram provocadas indiretamente pelos arranjos e movimentos diversos dos átomos (...) esses átomos constituíam, portanto, 0 verdadeiro núcleo objetivamente real da matéria e assim de todos os fenômenos. Eram (...) "aquilo que existe" no sentido mais estrito, enquanto a grande variedade de fenômenos só indiretamente decorria dos átomos. Por essa razão tal conceito era chamado de materialismo (HEISENBERG, 2004, p. 11 e 12).

A especificidade da interpretação de Heisenberg do atomismo grego, na verdade, reside na influência que, segundo ele, a idéia do materialismo teve na história subseqüente da ciência. A divisão entre qualidades primárias e secundárias, tão comum na obra de inúmeros filósofos e cientistas a partir do século XVII, tais como Galileu, Descartes, Locke e Boyle, teria origem no atomismo grego, na qual os dados sensíveis seriam redutíveis a átomos e vazio. Para o cientista moderno, as modificações 
qualitativas em nível macroscópico, percebidas pelos sentidos, podem ser reduzidas às variações quantitativas: a forma, tamanho e localização dos objetos. Estas últimas, as qualidades primárias, são objetivas e, portanto, suscetíveis de serem apreendidas pela razão. As qualidades secundárias, por outro lado, existiriam apenas na experiência perceptual do sujeito. Heisenberg afirma que essa distinção seria uma das mais profundas - e silenciosas - marcas do pensamento antigo na ontologia da ciência moderna:

Durante os últimos cem anos, a idéia democriteana do átomo tornou-se parte integrante da visão do mundo material dos físicos; ela era prontamente inteligível e intuitiva, a ponto de determinar o pensamento de muitos dentre os físicos que procuravam manter distância da filosofia (HEISENBERG, 1989, p. 82).

A influência do programa materialista/atomista é inegável. Heisenberg jamais nega o óbvio. Entretanto, a junção entre o materialismo de Demócrito, a metafísica cartesiana ${ }^{15}$ e a ênfase na descrição matemática da natureza, iniciada por Galileu no século XVI, acabou por encontrar, para Heisenberg, seu limite. Ora, mas como explicar o soçobrar do materialismo depois de séculos de sucesso?

0 materialismo moderno padeceria de uma série de limitações epistemológicas diante da Mecânica Quântica em função de suas raízes democritianas:

[nessas discussões acerca] dos conceitos de matéria e espaço, já encontramos o problema geral de qual é o real significado do termo "compreensão" da natureza. A teoria atomística de Demócrito levou a uma compreensão das qualidades da matéria ou acabou por prescindir de tal compreensão? Em que sentido a teoria "explica" o comportamento geométrico dos corpos? (HEISENBERG, 1952, p. 31).

0 problema, em outras palavras, era se o materialismo em seu curso histórico, com sua ênfase nas qualidades primárias e objetivas, abriu mão de certos aspectos essenciais da realidade. $\mathrm{Na}$ avaliação de Heisenberg, no transcorrer da história da ciência, a interpretação da natureza, Naturerklärung, foi gradativamente substituída pela descrição da natureza, Naturerbeschreibung, o que acarretou 0 abandono de um "conhecimento imediato e direto" e o predomínio de um "entendimento analítico" (HEISENBERG, 1952, p. 34).

Seria essa virada conceitual que acabaria por determinar a incompreensão que a teoria quântica recebeu desde seu início. Na tentativa de esclarecer as concepções de Naturerklärung e Naturerbeschreibung, Heisenberg busca auxílio na noção de Dianóia presente em Platão.

\section{Diánoia e epistéme}

No texto de $A$ República (PLATÃo, 509 c 5 511 e 5), utiliza-se a analogia da "linha dividida" na qual cada trecho corresponde a um tipo de objeto e ao processo de conhecimento correspondente. Ou seja, os significados relativos a cada trecho destacado na linha apresentam duas facetas: uma ontológica e outra epistêmica.

Segundo Ross (1976, p. 45), a linha é dividida em dois segmentos principais: um representa o mundo visível (tópos horatós) e o outro o mundo inteligível (tópos noetós). Ambos os segmentos correspondem, respectivamente, ao discurso fundado em meras opiniões (dóxa) e à verdade baseada nos conhecimentos legítimos (epistéme). 0 segmento de reta correspondente ao mundo visível se subdivide em outros dois: o inferior correspondente a todas as imagens derivadas de objetos sensiveis como sombras, reflexos em espelhos e na água. 0 outro segmento corresponderia a objetos sensiveis naturais e aos objetos fabricados pelos homens, que originariam os objetos do primeiro segmento.

Do ponto de vista epistêmico, o primeiro segmento, das sombras, corresponderia à mera ilusão, conjecturas ou imaginação (eikasía), e o segundo, à crença, à convicção (pístis). A eikasía seria um conhecimento incompleto, parcial e, no máximo, útil para o dia-a-dia do homem comum. Já a pístis seria um "conhecimento" relativamente mais estável, porém incapaz de se sustentar por conta própria, pois sua referência seriam os instáveis objetos do mundo material.

0 segundo segmento de reta principal corresponde, conforme dito, ao reino da verdade, ou
15. Sobre a crítica de Heisenberg ao materialismo posterior à Revolução Científica cf. LEITE; SIMON, 2010. 
seja, da investigação propriamente científica. É, quanto ao conhecimento, a epistéme, cujo objeto é o suprassensivel. A primeira metade desse trecho da linha corresponderia aos objetos matemático-

16. A existência ou não dessa classe é objeto de dissensão entre os platonistas: “Mas não vale o critério pelo qual aquilo que participa em igual medida do ser, tanto é verdade que 'só o que é plenamente conhecível? Então: não deduz da 'comparação da linha' a existência de uma realidade inteligível 'de segundo grau' em relação às Idéias, como objeto das ciências matemáticas? [Entretanto] Platão, em todos seus escritos, deixa de dizer explicitamente se existe o não uma realidade inteligíve 'intermediária', que seja objeto da dianoia matemática" (CATTANEI, 2005, p. 254 - 255). Mas, para Cattanei, a diánoia não pode se considerada um saber inferior dispensável (Ibid., p. 33) 17. Ver supra nota 6 . -geométricos ${ }^{16}$ e aos conhecimentos acerca deles: a diánoia. Mas esta ainda seria um conhecimento intermediário, mero pensamento, pois apesar da referência às Idéias, a diánoia ainda parte de "hipóteses estabelecidas com base em intuições sensoriais de figuras visíveis" (JAEGER, 2003, p. 881).

0 interesse de Heisenberg é centrado apenas nas noções de epistéme e de diánoia. 0 trecho a seguir revela como ele compreendia ambas:

Epistéme é precisamente o estado de consciência no qual se pode parar e para além do qual não é preciso mais pesquisar. Diánoia é a habilidade de analisar em detalhes o resultado da dedução lógica. Ao que parece, em Platão, apenas a epistéme fornece uma conexão com o verdadeiro, o essencialmente real, enquanto a diánoia, por mais que forneça de fato conhecimento, é um conhecimento desprovido de valores (HEISENBERG,

1974, p. 137).

0 trecho seguinte trata especificamente da diánoia:

Platão explica em detalhes a natureza do segundo estado de percepção e entendimento e como nós podemos alcançar este nível através do estudo da natureza. As leis matemáticas da natureza encontradas na base dos fenômenos naturais são, para ele, de importância primordial, comparada com a variedade de mudanças dos próprios fenômenos. (...) [É] importante e característico que Platão enfatize apenas este aspecto da ciência, aquele que nós ocasionalmente agora chamamos de 'formal'. [...] mas a percepção e entendimento da natureza que pode ser obtido pelo estudo das estruturas matemáticas é, para Platão, apenas o prelúdio para a melodia que é nosso real propósito aprender (HEISENBERG, 1952, p. 33).

De que modo esses dois conceitos servem de parâmetros heurísticos para uma melhor compreensão da dinâmica entre o materialismo e o idealismo no transcorrer da história? Para Heisenberg, além da influência da metafísica cartesiana sobre o materialismo moderno, este também se distingue do atomismo antigo, e de toda a filosofia grega, pelo fato de seu grande bastião, a ciência moderna, ter abandonado a noesis/epistéme como objetivo último e haver se limitado à descrição matemática do mundo, ou seja, ao campo da diánoia, ou nos termos de Heisenberg, da "Naturerbeschreibung", descrição da natureza.

A compreensão da natureza, durante os últimos cinco séculos, limitou-se a afastar os dados da experiência imediata e, subjacente a eles, descobrir estruturas matemáticas. 0 desafio levantado pela Mecânica Quantica forçava a ciência moderna para além da diánoia/Naturerbeschreibung e apontava para uma abordagem da natureza situada no campo epistêmico da noesis, ou seja, da interpretação da natureza, na visão de Heisenberg.

\section{Teoria quântica e idealismo: as simetrias platônicas e a estrutura da matéria}

Para o físico alemão, a descoberta de Plan$\mathrm{ck}^{17}$, em 1900, tornou-se uma oportunidade para reintroduzir o idealismo após séculos de predomínio materialista, pois o quantum de ação:

Conduziu à idéia de que a descontinuidade, assim como a existência do átomo, poderiam ser manifestações conjuntas de uma lei fundamental da natureza, de uma estrutura matemática na natureza, e que a sua formulação poderia conduzir a uma compreensão unificada da estrutura da matéria, que os filósofos gregos haviam procurado. A existência dos átomos, por conseguinte, não constituía, talvez, um fato último, incapaz de explicação ulterior. Essa existência poderia ser atribuída, assim como em Platão, à ação de leis da natureza matematicamente formuláveis, isto é, ao efeito de simetrias matemáticas (HEISENBERG, 2004, p. 13).

A crítica de Heisenberg à descrição da natureza efetuada pela ciência moderna anterior à Mecânica Quântica é complementada pela concepção de que a física contemporânea é refratária à 
Demócrito, e próxima de Platão (e, por conseguinte, dos pitagóricos).

Apropriando-se da passagem do Timeu sobre o isomorfismo entre os sólidos regulares (tetraedro, octaedro, icosaedro e cubo) e os quatro elementos materiais herdados da filosofia de Empédocles: fogo, ar, água e terra, Heisenberg estabelece semelhanças entre a Mecânica Quântica e o platonismo. As propriedades desses últimos seriam explicadas pelos primeiros $^{18}$, mas o reducionismo platônico realiza mais um passo:

Ora, todos os corpos apresentam profundidades, sendo de necessidade forçosa que a profundidade esteja encerrada na natureza da superfície e que toda superfície retilínea seja composta de triângulos (...) esta é a origem que atribuímos ao fogo e aos demais corpos, de acordo com o método que concilia a necessidade com probabilidade (Timeu $53 \mathrm{c}-\mathrm{d}$ ) ${ }^{19}$.

Cada um dos sólidos regulares é composto por triângulos que possibilitam que o fogo, a água e 0 ar possam ser transformados entre si, de modo que "através de um processo de decomposição dos primeiros três sólidos nos seus triângulos componentes e a recombinação destes, podemos transformar qualquer um dos três em qualquer outro" (ERICKSON; FOSSA, 1990, p. 96). Tal processo explica "como podem formar-se os mais belos corpos, quatro ao todo, dessemelhantes entre si, porém de tal maneira que uns podem ser gerados dos outros, por dissolução" (Timeu 53 d-e) $)^{20}$.

A questão que se coloca é então a seguinte: por qual razão Heisenberg relaciona a doutrina platônica com a estrutura da matéria segundo a física moderna? 0 trecho a seguir pode servir como introdução ao modo como Heisenberg interpreta a física platônica, no que se refere à estrutura da matéria:

Quando duas partículas elementares de elevada energia colidem, originam-se várias partículas no processo de desintegração, mas os fragmentos resultantes não são necessariamente menores do que as partículas iniciais. [...] o conceito de divisibilidade perdeu assim o seu significado, e, conseqüentemente, o mesmo aconteceu com o conceito de partícula mínima. Se a energia se converte em matéria, isso acontece porque a energia adota a forma equivalente de partículas elementares. Esta forma aparece como a representação de um grupo de transformação ${ }^{21}$, tal como a rotação no espaço ou a transformação de Lorentz. [...] elas são as entidades menores, autênticos blocos construtores da matéria, ou são elas meramente representações matemáticas dos grupos de simetria pela qual a matéria é construída? (HEISENBERG, 1990, p. 47).

Ao afirmar que o conceito de divisibilidade havia perdido seu significado, a própria noção de "partícula última", ponto final do processo de divisibilidade da matéria, estaria, consequentemente, também esvaziada de sentido - o que invalidaria todo o materialismo moderno. Mesmo a equivalência entre matéria e energia, prevista pela Relatividade Especial ${ }^{22}$, contribuiu para o colapso do materialismo, pois esta energia é descrita como um grupo de transformação - um conceito matemático diretamente relacionado com simetrias ${ }^{23}$. Simetrias seriam “as propriedades de um sistema que após dada operação é transformado num sistema indistinguível do original" (RODITI, 2005, p. 209).

Quando Heisenberg afirma que o átomo seria a "manifestação de uma lei fundamental da natureza, de uma estrutura matemática na natureza" (HEISENBERG, 2004, p. 13) ele rompe com a ciência moderna em sua faceta atomista/materialista e reforça o platonismo e seu realismo matemático que, se não existia no atomismo democritiano/ moderno, apenas radicaliza a crença galileana/ platônica da relação intrínseca entre a natureza e a matemática ${ }^{24}$. Contudo, Heisenberg recai num dilema quando aposta no platonismo: se o realismo matemático fornece um conteúdo ontológico que faltava à mera "descrição da natureza", ao mesmo tempo, tal compromisso ontológico vai de encontro às restrições epistemológicas tão caras a Heisenberg desde a década de 1920, quando da criação da Mecânica Quântica ${ }^{25}$. Ou seja, se as imagens do materialismo tradicional não respondem à altura à complexidade do mundo quântico, um realismo que crê na existência de simetrias matemáticas que substituam os átomos como fundamento último da realidade não se coaduna às teses antirrealistas da
18. Essa teoria chegou até a Idade Média, fundamentando não só a física, mas também disciplinas biológicas, médicas e psicológicas (ERICKSON; FOSSA, 1990, p. 85). Segundo John Loose (2000, p. 29), “a orientação pitagórica tornou-se influente no ocidente cristão principalmente como resultado do casamento do Timeu de Platão com a Sagrada Escritura". A influência da teoria platônica dos sólidos regulares é percebida, até mesmo, no início da Idade Moderna, na astronomia de Kepler.

19. Timeu, $53 \mathrm{c}-\mathrm{d}$.

20. Timeu, $53 \mathrm{~d}-\mathrm{e}$

21. Grupo de transformação é um conceito matemático que pode evidenciar a invariância de certas teorias físicas. Ou seja, certas equações permanecem as mesmas para certas mudanças em algumas variáveis, especialmente o espaço e o tempo. A ideia de invariância foi um dos conceitos centrais para a criação da teoria da relatividade de Einstein.

22. Representada pela famosa equação de Einstein, $E=m c^{2}$. 23. Cf. LEITE; SIMON, 2010. 24. Sobre as relações entre Platão, Galileu e a Revolução Científica, cf. HENRY, 1998; KOYRÉ, 2011; e ROSSI, 2001. 25. Cf. CHEVALLEY, 1992. 
Interpretação de Copenhague. Ou seja, existe na obra de Heisenberg uma oscilação entre epistemologia e ontologia, que pode ser descrita como uma tensão entre as restrições epistemológicas que 0 acompanham desde a invenção da mecânica quântica e a sua busca por um conteúdo ontológico que não recorresse às imagens do materialismo.

\section{Heisenberg entre Heráclito, Pitágoras e Aristóteles}

A resposta dada por Heisenberg a tal impasse seria um hibridismo entre o platonismo (para o qual as simetrias seriam parte desse fundamento) e 0 aristotelismo. Ao recorrer ao Estagirita, o físico germânico encontra outro suporte ontológico para a matéria além das simetrias: a energia.

Todas as partículas elementares são compostas da mesma substância, isto é, energia. Constituem as várias formas que a energia deve assumir a fim de se tornar matéria. No caso, reaparece o par de conceitos "conteúdo e forma" ou "substância e forma" da filosofia aristotélica. Energia não é apenas a força que mantém o "todo" em movimento contínuo; é também - como o fogo na filosofia de Heráclito - a substância fundamental de que é feito o mundo. A matéria origina-se quando a substância energia é convertida na forma de uma partícula elementar. Segundo os nossos conhecimentos atuais, há muitas formas desse tipo. Conhecemos cerca de 25 tipos de partículas elementares, e temos boas razões para crer que todas essas formas são manifestações de certas estruturas fundamentais, isto é, de uma lei fundamental matematicamente exprimível da qual as partículas elementares são a solução, assim como os vários estados energéticos do átomo de hidrogênio representam a solução da equação diferencial de Schrödinger. As partículas elementares são, pois, as formas fundamentais que a substância energia deve assumir a fim de converter-se em matéria, e tais formas básicas precisam de algum modo ser determinadas por uma lei fundamental exprimível em termos matemáticos (HEISENBERG, 2004, p.23).

A estrutura fundamental do mundo não seria puramente matemática. Haveria uma substância, a energia, sendo ela um suporte para as simetrias e leis matemáticas. É recorrente, nos textos de Heisenberg, a comparação entre energia, essa "substância universal", e o Fogo dos fragmentos heraclíticos. Heisenberg chega a ponto de afirmar que, se substituirmos a palavra "fogo" por "energia" nos escritos do filósofo de Éfeso, “podemos repetir suas afirmações, palavra por palavra, segundo nosso ponto de vista moderno" (HEISENBERG, 1995, p.52).

A energia, nesse caso, teria a função que 0 conceito de arché tem nos pré-socráticos: “matéria original constitutiva das coisas, que persiste como substrato e na qual elas se convertem e perecem" (KIRK, 1994, p. 87). Segundo Barnes (2003, p. 22), arché pode significar tanto "começo", "principio" como "poder" ou "comando", não sendo apenas um princípio originário, mas também regulador do cosmos. A energia, para Heisenberg:

[...] é, de fato, substância da qual são feitas todas as partículas elementares, átomos e, portanto, todas as coisas e é também aquilo que as move. A energia é uma substância porque sua quantidade total não muda, e as partículas elementares podem de fato ser formadas dessa substância, conforme se observa em muitas experiências sobre a criação dessas partículas (HEISENBERG, 1996, p. 52).

Além da simetria, que regeria as transformações entre as partículas, existiria outro aspecto fundamental da natureza que seria invariante: $a$ substância energia.

\section{Conclusão}

Pode-se afirmar que há em Heisenberg uma ontologia realista, a qual se exprime pelo fundamento da matéria baseado na coadunação entre estruturas matemáticas, uma herança platônica, com a energia - análoga à arché dos pré-socráticos, particularmente com o fogo heraclitiano. Entretanto, é um realismo atípico, pois precisa incluir as noções de probabilidade e medida, em função da relação entre os níveis de realidade quântico e clássico e seus regimes nomológicos diversos. Como uma forma de mediar esses dois níveis e de enxertar o ato de 
observação nesse cenário, Heisenberg acrescenta a noção aristotélica de potência ${ }^{26}$. A conseqüência é a proposta de um novo nível de realidade fundamentado na probabilidade. Heisenberg chega, assim, a um realismo estrutural, mantendo o energetismo, mas incluindo a noção de probabilidade, tão cara à Mecânica Quântica. Mas o energetismo parece necessitar da filosofia aristotélica, pois a energia, como ele mesmo escreve acima, seria a substância, ao passo que a estrutura matemática, particularmente as simetrias, poderiam corresponder à forma em Aristóteles. Não surpreende que no texto que cunhou o termo "Interpretação de Copenhague" (HEISENBERG, 1955, p. 16), também se proclame o fato de que a teoria quântica, na verdade, trata de uma "nova realidade física objetiva" - realidade essa apreendida também em termos aristotélicos ${ }^{27}$.

Se o percurso filosófico de Heisenberg é povoado por certas incoerências, ecletismos peculiares e mesmo pela ausência de rigor num grau intolerável a leitores filosoficamente exigentes, tal constatação invalidaria a priori as teses filosóficas de Heisenberg acerca da natureza da matéria? Não parece ser o caso. A elaboração de um pensamento coerente e sistemático é uma exigência que grande parte dos filósofos fazem para si mesmos e seus pares. Heisenberg, apesar de seus interesses na filosofia, nunca pretendeu ser um filósofo, pelo menos não um filósofo profissional. Por mais que seu discurso filosófico fosse subdeterminado pelos seus interesses científicos, isso não impossibilita que se extraia dele reflexões importantes sobre o estatuto da matéria no contexto da teoria quântica.

Heisenberg busca na filosofia clássica uma fonte de ontologias para uma nova física, que parecia refratária a tal fundamentação. 0 físico alemão encontra nos escritos daquele período antecedentes importantes às ideias da teoria quântica, mesmo se em um nível estritamente qualitativo. Ou seja, as ontologias possíveis para a natureza, mesmo num domínio tão pouco intuitivo, não são abandonada. Fazendo uso dessas ontologias, Heisenberg mostra o quanto os autores do período clássico tiveram intuições importantes para compreender o substrato da matéria. Para ele, a Mecânica Quântica, mesmo com seu complexo formalismo, não invalidou de todas essas intuições. Na verdade, para Heisenberg, essas intuições foram importantes para a compreensão e mesmo para a consolidação da Mecânica Quântica.

\section{Referências Bibliográficas}

ARISTÓTELES. (2004). Metafísica. Tradução, introdução e notas de Lucas Angioni. Campinas, IFCH/UNICAMP, novembro.

(2007) Metaphysics. Tradução de Hugh Tredennick. Disponivel em: <http://www.perseus.tufts.edu/cgi-bin/ ptext?lookup=Aristot.+Met.+7.1029a. $>$ Acesso em: 12 de agosto.

BARNES, J. (2003). Filósofos pré-socráticos. São Paulo, Martins Fontes.

BOHM, D. (1951). Quantum theory. New York, Dover Publications.

BOHR, N. (1981). A descrição da realidade física fornecida pela mecânica quântica pode ser considerada completa? Cadernos de História e Filosofia da Ciência, Campinas, n. 2, p. 97-106, (original de 1935).

- (1995). Física atômica e conhecimento humano. Rio de Janeiro, Contraponto, (original de 1958).

(2000). 0 Postulado Quântico e o Recente Desenvolvimento da Teoria Atômica. In: PESSOA JR., 0. (org.). Fundamentos da física 1 - Simpósio David Bohm. São Paulo, Livraria da Física, p. 135 - 159.

BURNET, J. (2006). A aurora da filosofia grega. Rio de Janeiro, Contraponto.

CARTLEDGE, P. (2001). Demócrito. São Paulo, UNESP.

CATTANEI, E. (2005). Entes matemáticos e metafísica: Platão, a Academia e Aristóteles em confronto. São Paulo, Loyola.

CHEVALLEY, C. (1992). La physique quantique et les grecs. In: CASSIN, B. (org.) Nos grecs et leurs modernes - Les stratégies contemporaines d'appropriation de l'antiquité. Paris, Éditions Gallimard.

CHIBENI, S. (1992). Implicações filosóficas da microfísica. Cadernos de História e Filosofia da Ciência, Campinas, Série 3, n. 2, v. 2, p.141-164, jul.-dez.

CORNFORD, F. M. (1957). From Religion to Philosophy: a study in the origins of the western speculation. Princeton, Princeton University Press.

ERICKSON, G. ; FOSSA, J. (1990). Os sólidos geométricos na antigüidade. Cadernos de História e Filosofia da Ciência, Campinas, Série 2, n. 2, v. 1, p. 85-101, jan.-jun.

EINSTEIN, A.; PODOLSKY, B.; ROSEN, N. (1981). On a heuristic point of view about the creation and conversion of light. A descrição da realidade física fornecida pela Mecânica Quântica pode ser considerada completa? Cadernos de História e Filosofia da Ciência, Campinas, n. 2, p.90-96.

FREIRE JR., 0. (2011). Dissidentes Quânticos, In: FREIRE
26. Para o uso que Heisenberg faz dos conceitos Aristotélicos de potência e ato cf. CHEVALLEY, 1992.

27. 0 uso que Heisenberg faz da filosofia aristotélica será objeto de um artigo em preparação pelos autores. 